\title{
Коллекционный фонд травянистых декоративных представителей широколиственных лесов ГБС РАН как элемент сохранения биоразнообразия
}

\section{Collections of herbaceous ornamental representatives of the deciduous forests of the MBG as an element of biodiversity conservation}

\author{
Хохлачева Ю. А. \\ Khokhlaheva J. A. \\ Главный ботанический сад им. Н. В. Цииина РАН, г. Москва, Россия. E-mail: jusic-la@yandex.ru \\ Main Botanical Garden named after N. V. Tsitsin RAS, Moscow, Russia
}

\begin{abstract}
Peфepam. Основная направленность деятельности ботанических садов - сохранение и обогащение региональных культурных флор декоративных растений путем привлечения и испытания в культуре новых видов. Коллекция-экспозиция «Теневой сад» Главного ботанического сада - одно из крупнейших в Европе собраний теневыносливых декоративных многолетников. Многолетние исследования, которые проводятся сотрудниками сада, позволяют определить перспективность исследуемых растений и предложить для широкого использования в культуре в средней полосе России около 150 видов перспективных и очень перспективных декоративных травянистых многолетников.
\end{abstract}

Ключевые слова. Главный ботанический сад, коллекция-экспозиция, культурная флора, теневой сад, теневыносливые многолетники.

Summary. The main focus of botanical gardens is the preservation and enrichment of regional cultivated flora of ornamental plants through the attraction and testing of new plant species in culture. The collection-exposition "Shadow Garden" of the Main Botanical Garden is one of the largest collections of shade-tolerant decorative perennials in Europe. Long-term studies, which are conducted by garden staff, allow us to determine the prospects of the plants studied in culture and offer about 150 species of promising and very promising ornamental herbaceous perennials for widespread use in culture in central Russia.

Key words. Collection exposition, cultural flora, Main Botanical Garden, shadow Garden, shade-tolerant perennials.

Исторически сложилось так, что только коллекции ботанических садов (в первую очередь крупнейшая из них - Главного ботанического сада им. Н. В. Цицина Российской академии наук (ГБС РАН)) стали основой генофонда цветочно-декоративных растений, в котором отражается все биоразнообразие декоративных растений (Карписонова, 2011).

Травянистые представители широколиственных лесов в Главном ботаническом саду располагаются на территории коллекции-экспозиции «Теневой сад». Она находится на западной опушке Останкинской дубравы. Это одна из старейших коллекций Главного ботанического сада, которая в настоящий момент занимает площадь 0,7 га. Участок является уникальным, так как в нем представлено видовое разнообразие травянистых многолетников широколиственных лесов Европы, Азии, Америки. Коллекция «Теневой Сад» - одно из крупнейших в мире собраний теневыносливых растений.

Коллекцию теневыносливых и тенелюбивых растений начала собирать М. С. Благовидова, с 1973 г. куратором группы стала Р. А. Карписонова. В отличие от монокультур основой отбора видов является разработанный в отделе эколого-ценотический метод (Карписонова, 1985).

Исследования в природе показали, что травянистый ярус широколиственных лесов из всех типов леса наиболее богат декоративными видами (Вальтер, 1974). Экспедиционные поездки, которые 
были организованы в 1970-1980-х гг. ХХ в., позволили сотрудникам Главного ботанического сада собрать одну из самых крупных коллекций представителей широколиственных лесов в Европе. В начале 90-х годов прошлого века она насчитывала порядка 800 видов.

Одним из первых пополнений стало поступление зарубежного посадочного материала (Германия в 1946 г.; Бельгия в 1950 г.; Швейцария в 1951 г.). Постепенно коллекция пополнялась за счет природных видов, привезенных из экспедиций ГБС РАН. На сегодняшний день в экспозиции «Теневой сад» есть ряд растений, которые вот уже более 65 лет растут на этом участке: хоста Зибольда (Hosta sieboldiana (Hook.) Engl.), х. волнистая (H. undulata (Otto et Dietr.) Bailey), пахизандра верхушечная (Pachysandra terminalis Sieb. et Zucc.), горянки (Epimedium L.), роджерсия конскокаштанолистная (Rodgersia aesculifolia Batal.), p. перистая (R. pinnata Franch.), p. бузинолистная (R. sambucifolia Hemsl.). Они прошли проверку временем, испытав экстремальные зимы, засуху. Эти высокодекоративные растения оказались долговечными, устойчивыми, способными к самовозобновлению.

Около 5 \% имеющихся в коллекции видов были впервые испытаны в условиях средней полосы России. Многие из них оказались очень перспективны в культуре, некоторые в настоящее время успешно экспонируются на территории коллекции-экспозиции (Allium paradoxum (Bieb.) G. Don., Arisaema robustum (Engl.) Nakai, Sedum stoloniferum S.G. Gmel, Streptopus rosea Michx.).

Нами было определено 150 видов как перспективных и очень перспективных в культуре, благодаря длительным регулярным наблюдениям по методике, которая была разработана сотрудниками Главного ботанического сада (Былов, Карписонова, 1978).

Одним из важных показателей для отбора растений является показатель длительности жизни (Карписонова, 1999). Многолетними растениями называются те, которые на одном месте без деления и пересадки, а также без потери декоративности растут более двух лет. Существуют так называемые малолетники, которые требуют частой пересадки, каждые 3-4 года. Настоящие многолетники - это культуры, которые на одном месте растут более 5-6 лет. Кроме того, среди многолетников можно выделить долголетние многолетники, которые на одном месте растут 12 лет и более (Карписонова, 1985).

На базе коллекции-экспозиции «Теневой сад», которая существует с 1973 года, нами было решено выделить ряд растений, который можно назвать долголетними, так как они произрастают на одном месте в течение более 12 лет (Декоративные многолетники ..., 1960; Цветочно-декоративные травянистые растения ..., 1983; Травянистые декоративные многолетники..., 2009):

- представители рода Хоста (Hosta L.) - короткокорневищные многолетники; родина - леса Восточной Азии;

- пахизандра верхушечная (Pachysandra terminalis) - длиннокорневищный полукустарничек; родина - Китай, Япония;

- представители рода Горянка (Epimedium) - длиннокорневищные многолетники; родина - Cpeдиземноморье, Китай, Япония;

- представители рода Роджерсия (Rodgersia A. Gray) - длиннокорневищные многолетники с коротким отрастанием корневища; родина - леса Восточной Азии;

- симплокарпус вонючий (Symplocarpus foetidus (L.) Salisb. ex Nutt.) - короткокорневищный многолетник; родина - Дальний Восток и Северная Америка;

- представители рода Белокопытник (Petasites Mill.) - длиннокорневищные многолетники; родина - леса Европы, Дальнего Востока;

- подофиллум щитовидный (Podophyllum peltatum L.) - длиннокорневищный многолетник; родина - Северная Америка;

- ландыш майский (Convallaria majalis L.) - длиннокорневищный многолетник; родина - леса Евразии;

- представители рода Купена (Polygonatum Mill.) - длиннокорневищный многолетники; родина леса Евразии, Северная Америка;

- представители рода Волжанка (Aruncus Schaeffer) - короткокорневищные многолетники; родина - широколиственные леса Евразии, Северная Америки;

- представители рода Джефферсония (Jeffersonia Barton) - короткокрневищные многолетники; родина - леса Дальнего Востока и Северной Америки; 
- представители рода Вальдштейния (Waldsteinia Willd.) - короткокорневищные многолетники; родина - леса Евразии и Северной Америки;

- адиантум стоповидный (Adiantum pedatum L.) - короткокорневищный многолетник; родина Дальний Восток;

- представители рода Кочедыжник (Athyrium Roth.) - короткокорневищные многолетники; родина - средняя полоса России, Дальний Восток, Северная Америка;

- листовик сколопендровый (Phyllitis scolopendrium (L.) Newm.) - короткокорневищный многолетник; родина - широколиственные леса Европы, Кавказ;

- представители рода Щитовник (Dryopteris Adans.) - длиннокорневищные многолетники; родина - умеренная зона Северного полушария;

- оноклея чувствительная (Onoclea sensibilis L.) - длиннокорневищный многолетник; родина Восточная Азия, Северная Америка;

- представители рода Многорядник (Polystichum Roth.) - короткокорневищные многолетники; родина - Дальний Восток, Северная Америка, Европа;

- лабазник камчатский (Filipendula kamtschatica (Pall.) Maxim.) - короткокорнвищный многолетник; родина - Дальний Восток;

- пельфитифиллум щитовидный (Peltiphyllum peltatum (Torr.) Engl.) - длиннокорневищный многолетник; родина - Северная Америка;

- толстостенка крупнолистная (Pachyphragma macrophyllum (Hoffm) N. Busch.) - короткокорневищный многолетник; родина - леса Кавказа.

Таким образом, можно сказать, что все представленные долголетние многолетники по типу и структуре подземных органов относятся к короткокорневищным (вегетативно неподвижным) и длиннокорневищным (вегетативно подвижным) (Безделев, Безделева, 2006). В первом случае на одном месте в течение многих лет растет один и тот же куст. Тогда как во втором случае, растения постоянно меняются, но сохраняют, благодаря постоянному вегетативному возобновлению, «пятно». Длиннокорневищные растения обладают наибольшей вегетативной подвижностью и имеют ряд преимуществ перед растениями других жизненных форм, благодаря способности выносить дочерние почки возобновления в сторону от материнского побега.

Все представленные растения в природе произрастают в умеренной зоне Евразии, также в Северной Америке. Но большая часть долголетних многолетников родом с Дальнего Востока и Северной Америки.

\section{ЛИТЕРАТУРА}

Безделев А. Б., Безделева Т. А. Жизненные формы семенных растений российского Дальнего Востока. - Владивосток: Дальнаука, 2006. - 296 с.

Былов В. Н., Карписонова Р. А. Принципы создания и изучения коллекции малораспространенных декоративных многолетников // Бюл. Гл. ботан. Сада АН СССР, 1978. - Вып. 107. - С. 77-82.

Вальтер Г. Растительность земного шара. - М.: Прогресс, 1974. - Т. 2. - 423 с.

Декоративные многолетники. Краткие итоги интродукции в Главном ботаническом саду. - М.: Изд-во АН CCCP, 1960. - $185 \mathrm{c}$.

Карписонова Р.A. Травянистые растения широколиственных лесов СССР. Эколого-флористическая и интродукционная характеристика. - М.: Наука, 1985. - 205 с.

Карписонова P. A. Сад в тени. - М.: Издательство «Культура и традиции», 1999. -199 с.

Карписонова $\boldsymbol{P}$. $\boldsymbol{A}$. Коллекция-экспозиция «Теневой сад»// Особенности экспонирования коллекций декоративных растений. - М.: Товарищество научных изданий КМК, 2011. - Вып. 2. - С. 90-93.

Травянистые декоративные многолетники Главного ботанического сада им. Н. В. Цицина Российской академии наук. - М.: Наука, 2009. - 396 с.

Цветочно-декоративные травянистые растения. Краткие итоги интродукции. - М.: Наука, 1983. - 272 с. 